\title{
Reversal of Shortened Platelet Survival in Rats by the Antifibrinolytic Agent, Epsilon Aminocaproic Acid
}

\author{
P. D. Winocour, R. L. Kinlough-Rathbone, M. Richardson, and \\ J. F. Mustard, Department of Pathology, McMaster University, \\ Hamilton, Ontario, L8N 3Z5, Canada
}

\begin{abstract}
A B S TRACT Platelet survival in rabbits and rats is shortened by placing indwelling catheters in the aorta; this shortening appears to be at least partly related to the extent of vessel wall injury and platelet interaction with the repeatedly damaged wall. Treatment of rabbit platelets with plasmin and other proteolytic enzymes in vitro shortens their survival when they are returned to the circulation. Because platelets may be exposed to plasmin and other proteolytic enzymes in rabbits and rats with indwelling aortic catheters, we examined the effect of $\epsilon$-aminocaproic acid (EACA) on platelet survival in rats. At a dose of $1 \mathrm{~g} / \mathrm{kg}$ every $4 \mathrm{~h}$, EACA significantly reduced whole blood fibrinolytic activity and prolonged the shortened platelet survival in rats with indwelling aortic catheters. Mean platelet survival for untreated rats with indwelling aortic catheters was $38.6 \pm 1.9 \mathrm{~h}$, and for rats treated with EACA, 53.8 $\pm 3.8 \mathrm{~h}$. Scanning electron microscopy showed that the injured vessel wall of these animals was mainly covered with platelets and fibrin, whereas in control animals that did not receive EACA, the injured surface was mainly covered with platelets and little fibrin was observed. Thus shortened platelet survival during continuous vessel wall injury may result from the local generation of plasmin or the release of proteolytic enzymes at sites where platelets (and possibly leukocytes) interact with the vessel wall.
\end{abstract}

\section{INTRODUCTION}

We and others have found in experiments in rabbits and rats that repeated vessel injury caused by indwelling aortic catheters shortens platelet survival (1-

Dr. Winocour was a Postdoctoral Fellow of the Ontario Heart Foundation. Dr. Kinlough-Rathbone was the recipient of a Research Associateship of the Ontario Heart Foundation. Address reprint requests to $\mathrm{Dr}$. Kinlough-Rathbone.

Received for publication 9 February 1982 and in revised form 28 September 1982.
4). ${ }^{1}$ In other experiments we have shown that the reduction of platelet survival cannot be solely attributed to platelet accumulation in thrombi associated with the damaged vessel wall or catheters but seems to be related at least in part to the extent of vessel wall injury and platelet interaction with the damaged vessel wall. ${ }^{1}$ Exposure of platelets to ADP, thrombin, or thromboxane $A_{2}$ with which platelets are likely to come in contact during thrombus formation, does not shorten platelet survival $(5,6)$. However, proteolytic enzymes that cleave platelet membrane glycoproteins do shorten platelet survival (7). Thus, a possible mechanism by which the damaged vessel wall might modify platelets and shorten platelet survival is through the local activation of plasmin or other proteolytic enzymes; these enzymes could modify the platelets associated with the damaged wall so that when the platelets are lost from the injury site they are cleared from the circulation. To determine whether local activation of the fibrinolytic mechanism might be involved in shortened platelet survival, we have examined the effect of the antifibrinolytic agent $\epsilon$-aminocaproic acid (EACA) ${ }^{2}$ on shortened platelet survival induced by indwelling aortic catheters in rats.

\section{METHODS}

Platelet survival studies. Suspensions of twice washed platelets were prepared from blood obtained from the exposed hearts of several Wistar rats anesthetized with ether (8). ${ }^{1}$ The platelets were labeled with $\mathrm{Na}_{2}{ }^{51} \mathrm{CrO}_{4}(100-400$ $\mathrm{mCi} / \mathrm{mg} \mathrm{Cr}$; Amersham/Searle, Arlington Heights, IL; 50 $\mu \mathrm{Ci} / \mathrm{rat}$ ) in the first washing solution, washed once in calcium-free Tyrode's solution and suspended at a concentration of $1.5-2.5 \times 10^{9}$ platelets $/ \mathrm{ml}$ in the same plasma from which the platelets had been prepared. The labeled platelets

\footnotetext{
${ }^{1}$ Winocour, P. D., M. Cattaneo, D. Somers, M. Richardson, R. L. Kinlough-Rathbone, and J. F. Mustard. Submitted for publication.

${ }_{2}^{2}$ Abbreviation used in this paper: EACA, 6 -aminocaproic acid.
} 
( $1 \mathrm{ml}$ ) were injected through a $27 \mathrm{G}$ needle into a superficial penile vein of rats anesthetized with ether. The radioactivity of samples $(100 \mu \mathrm{l})$ of the platelet suspension was determined in a gamma counter and the total amount of radioactivity injected into each rat was calculated. Samples of blood were taken into heparinized micro-hematocrit tubes (DADE Division, American Hospital Supply Corporation, Miami, FL) from freshly cut ends of the tails of rats anesthetized with ether. Blood samples were centrifuged in a micro-hematocrit centrifuge (International Equipment Company, Needham Heights, MA) and after recording the hematocrits and lengths of the columns of blood, the radioactivity of the sample was determined in a gamma counter. Using the weight of known lengths of water in a number of microhematocrit tubes, a standard diameter of the tubes was established. Knowing the length of the column of blood collected and the radioactivity of the sample, the radioactivity of each sample per milliliter of blood was calculated. The labeled platelets were injected into the rats $18 \mathrm{~h}$ before the catheter was introduced. The first blood sample, taken just before the catheter was introduced, was assigned a value of $100 \%$. Blood samples were taken $3,6,9$, and $11 \mathrm{~h}$ after insertion of the catheter. Radioactivity in the samples was determined and the mean platelet life span was calculated from the radioactivity in individual samples using the gamma function described by Murphy and Bolling (9) and Scheffel et al. (10). The computer program for these calculations was kindly supplied by Dr. E. A. Murphy, Johns Hopkins University, School of Medicine, Baltimore, MD. By ensuring that the samples were always collected at the same time and by using the same number of samples in the calculations, it was possible to avoid the large variations in the calculated platelet survival values that have been reported by others (11).

Insertion of indwelling aortic catheters. The right femoral arteries of rats anesthetized with sodium pentobarbital $(40-60 \mathrm{mg} / \mathrm{kg})$ were isolated close to the aortic bifurcation. A polyethylene catheter (PE 10, Clay Adams, Becton, Dickinson \& Co., Parsippany, NJ) was sealed at one end with wax and introduced into the aorta via the femoral artery; the catheter extended $12.5 \mathrm{~cm}$ from the point of insertion. The femoral artery was ligated with the catheter in place and the incision closed with silk sutures.

Control animals had their femoral artery exposed and ligated in a "sham operation." Surgery was performed immediately after the first blood sample was taken.

$11 \mathrm{~h}$ after a sham operation or insertion of the catheters, the animals were given an injection of heparin $(500 \mathrm{U} / \mathrm{kg}$ intravenously; Hepalean, Harris Laboratories, Brantford, Ontario) and exsanguinated from the exposed heart under ether anesthesia. The aorta at the aortic arch and left femoral artery were both cut and blood was removed from the aorta by washing it through with $\sim 7 \mathrm{ml}$ of Tyrode's solution containing heparin $(5 \mathrm{U} / \mathrm{ml})$. The aortae were removed from the animals, dissected free of extraneous tissue, and cut into segments of $\sim 2.5 \mathrm{~cm}$. Each segment was placed in $4 \%$ paraformaldehyde in phosphate buffer $(2 \mathrm{ml}), \mathrm{pH} 7.35$. The radioactivity associated with each segment was determined and calculated as a percentage of the total radioactivity circulating when the first blood sample was taken. The same samples were kept for scanning electron microscopy.

Administration of EACA. Animals were given EACA (Sigma Chemical Co., St. Louis, MO), $1 \mathrm{~g} / \mathrm{kg}$ in $3 \mathrm{ml}$ of tap water; or placebo (tap water) orally $3 \mathrm{~h}$ before surgery, at the time of surgery and 4 and $8 \mathrm{~h}$ after surgery. No ill effects were observed with this dose of EACA.

Measurement of fibrinolysis. Whole blood fibrinolysis was determined by a modification of the method of Moroz and Gilmore (12). ${ }^{125} \mathrm{I}-\mathrm{Fibrin}$-coated tubes were prepared, filled with Tyrode's solution containing $0.1 \%$ sodium azide, and stored at $4^{\circ} \mathrm{C}$. Before use, the tubes were washed three times with Tyrode's solution. Blood samples $(0.9 \mathrm{ml})$ were taken into heparin $(0.1 \mathrm{ml}$ of $100 \mathrm{U} / \mathrm{ml})$ in triplicate $8 \mathrm{~h}$ after starting the treatment, pipetted into ${ }^{125}$ I-fibrin-coated tubes and incubated at $37^{\circ} \mathrm{C}$ for $1 \mathrm{~h}$. After $1 \mathrm{~h}$, Tyrode's solution $(2 \mathrm{ml})$ containing heparin $(10 \mathrm{U} / \mathrm{ml})$ was added rapidly to each tube and the contents poured into fresh tubes. Blood was rinsed from the ${ }^{125}$ I-fibrin-coated tubes with a further $1 \mathrm{ml}$ of Tyrode's solution containing heparin and pooled with the rest of the blood sample. Radioactivity of both tubes was determined in a gamma counter. Radioactivity from both tubes was added together and the radioactivity of the blood in the uncoated tube was expressed as a percentage of the total and considered as the percentage fibrinolysis.

Platelet aggregation. Blood was collected into heparin $(10 \mathrm{U} / \mathrm{ml})$ or trisodium citrate $(0.31 \%) 8 \mathrm{~h}$ after the EACA treatment was begun and platelet-rich plasma obtained by centrifugation at $1,800 \mathrm{~g}$ for $3 \mathrm{~min}$. The platelet count was adjusted to $10^{9}$ platelets per $\mathrm{ml}$ with platelet-poor plasma. Platelet aggregation to ADP, collagen or sodium arachidonate (Sigma Chemical Co) was measured in an aggregometer (Chronolog Corporation, Havertown, PA) (13). The collagen and sodium arachidonate were prepared as previously described $(14,15)$.

Scanning electron microscopy. Sections from the thoracic aortae from two animals in each group were examined by scanning electron microscopy (16). The extent of fibrin formation on the aorta surface was determined independently by three investigators (who were unaware of the treatment group) by placing a 10- $\mu \mathrm{m}$ grid on each micrograph and recording the presence or absence of fibrin strands on each 10 square $\mu \mathrm{m}$.

\section{RESULTS}

In these experiments, the indwelling aortic catheters of the size and type used did not induce macroscopic thrombus formation in rats. EACA at a dose of $1 \mathrm{~g} / \mathrm{kg}$ every $4 \mathrm{~h}$ significantly prolonged the shortened platelet survival observed in animals with the indwelling aortic catheters (Table I).

The whole blood fibrinolytic activity was significantly reduced in EACA-treated animals. The percentage of ${ }^{125}$ I-fibrin digested by whole blood from placebo-treated rats was $4.5 \pm 0.7 \%$, whereas $0.7 \pm 0.1 \%$ was digested by blood from EACA-treated rats $(P<0.01)$.

The dose of EACA used to treat the rats did not inhibit the aggregation of platelets in heparinized plasma in response to ADP $(0.2$ or $1.5 \mu \mathrm{M})$, sodium arachidonate $(0.15$ or $0.25 \mathrm{mM})$ or collagen. A similar lack of inhibitory effect of EACA on platelet aggregation was observed for platelets in citrated plasma.

The aortic surfaces of animals with indwelling aortic catheters were examined by scanning electron microscopy. The surfaces of the vessels from animals treated with EACA had platelets and fibrin associated 
TABLE I

Effect of EACA on Platelet Survival and Association of ${ }^{51} \mathrm{Cr}$ with Aortae of Rats with Indwelling Aortic Catheters or Sham Operations

\begin{tabular}{|c|c|c|c|c|}
\hline Treatment $^{\bullet}$ & $\begin{array}{l}\text { Platelet survival, } \\
\text { mean } \pm \text { SE }\end{array}$ & $\begin{array}{l}\text { Significance of difference } \\
\text { between means }\end{array}$ & $\begin{array}{l}{ }^{31} \mathrm{Cr} \text { Associated with the } \\
\text { aorta mean } \pm \mathrm{SE}\end{array}$ & $\begin{array}{c}\text { Significance of difference } \\
\text { between means }\end{array}$ \\
\hline & $h$ & & \% total in circulation at zero time & \\
\hline Placebo + sham operation (9) & $70.5 \pm 4.4$ & & $0.057 \pm 0.014$ & \\
\hline & & $P<0.001$ & & $P<0.05$ \\
\hline Placebo + aortic catheter $(10)$ & $38.6 \pm 1.9$ & $P<0.01$ & $0.121 \pm 0.021$ & NS \\
\hline EACA + aortic catheter $(9)$ & $53.8 \pm 3.8$ & $P<0.001$ & $0.307 \pm 0.116$ & $P<0.05$ \\
\hline EACA + sham operation (9) & $78.9 \pm 4.9$ & & $0.055 \pm 0.006$ & \\
\hline
\end{tabular}

- EACA was given orally $3 \mathrm{~h}$ before insertion of the catheter, at the time of its insertion and at 4-h intervals thereafter. The numbers in parentheses are the number of rats in each group. The significance of the difference between means was calculated by Student's $t$ test.

with them in contrast to animals not given EACA and in which the injured surfaces were mainly covered by a layer of platelets (Figs. 1A and B). Morphometric assessment of the electron micrographs showed that of the 180 sections (each of 10 square $\mu \mathrm{m}$ ) examined for animals treated with EACA, 108 had fibrin associated with the surface $(60 \%)$. In contrast, only 26 sections out of the 178 sections examined for placebotreated animals had fibrin on the surface (15\%). In addition, the amount of ${ }^{51} \mathrm{Cr}$ associated with the aortae at the completion of the experiments tended to be increased in animals given EACA compared to the animals given only the placebo (Table I).

\section{DISCUSSION}

The observation that shortened platelet survival in rats with indwelling aortic catheters returns towards normal when rats are given EACA, is in keeping with the hypothesis that proteolytic enzymes, possibly plasmin, may modify platelets that come in contact with the injured vessel wall leading to rapid clearance of these platelets from the circulation when they leave the vessel wall. In other experiments it has been shown that modification of platelet membrane glycoproteins by proteolytic enzymes, such as plasmin, causes their rapid clearance from the circulation (7). Platelet glycoproteins may be involved in platelet adherence to exposed subendothelium (17). It is possible that local release or activation of proteolytic enzymes by the cells in the vessel wall or proteolytic enzymes released from leukocytes may cleave surface proteins or glycoproteins of platelets adherent to the wall, leading to loss of platelets from the subendothelium and an increased rate of clearance of these altered platelets from the circulation. The EACA-treated animals with indwelling aortic catheters had nearly three times as much ${ }^{51} \mathrm{Cr}$ associated with the surface of the vessel $11 \mathrm{~h}$ after insertion of the catheter. Since the amount of ${ }^{51} \mathrm{Cr}$ on the surface is the net radioactivity resulting from platelet loss and platelet accumulation, this increased radioactivity could be a result of decreased loss of platelets from the surface of the vessel wall or increased platelet accumulation at the injury sites.

Evidence that treatment with the antifibrinolytic agent inhibited proteolytic activity was obtained from the observation that extensive deposits of fibrin were found on the vessel wall of some treated animals but were not found in untreated controls. Vessel walls contain plasminogen activator that can be released from the tissues; there do not appear to have been detailed studies of whether the smooth muscle cells of the vessel wall, in addition to the endothelial cells, contain plasminogen activator (18). Astrup and Buluk (19) examined the fibrinolytic activity of the blood vessels of a number of species and found that in rats the intima and media together did have fibrinolytic activity; these authors were not able to localize this activity more accurately, however. Leukocytes have proteolytic activity and their interaction with the vessel wall may result in the release of additional proteolytic enzymes that could influence platelet interaction with the injured vessel wall (20).

In studies in man, fibrinolytic therapy was not found to influence platelet survival (21), although there is some evidence that subjects with cirrhosis of the liver who have increased fibrinolytic activity do show shortened platelet survival (22). Ordinas et al. (23) have shown that platelets from such patients have altered platelet membrane glycoproteins. It is unlikely that 

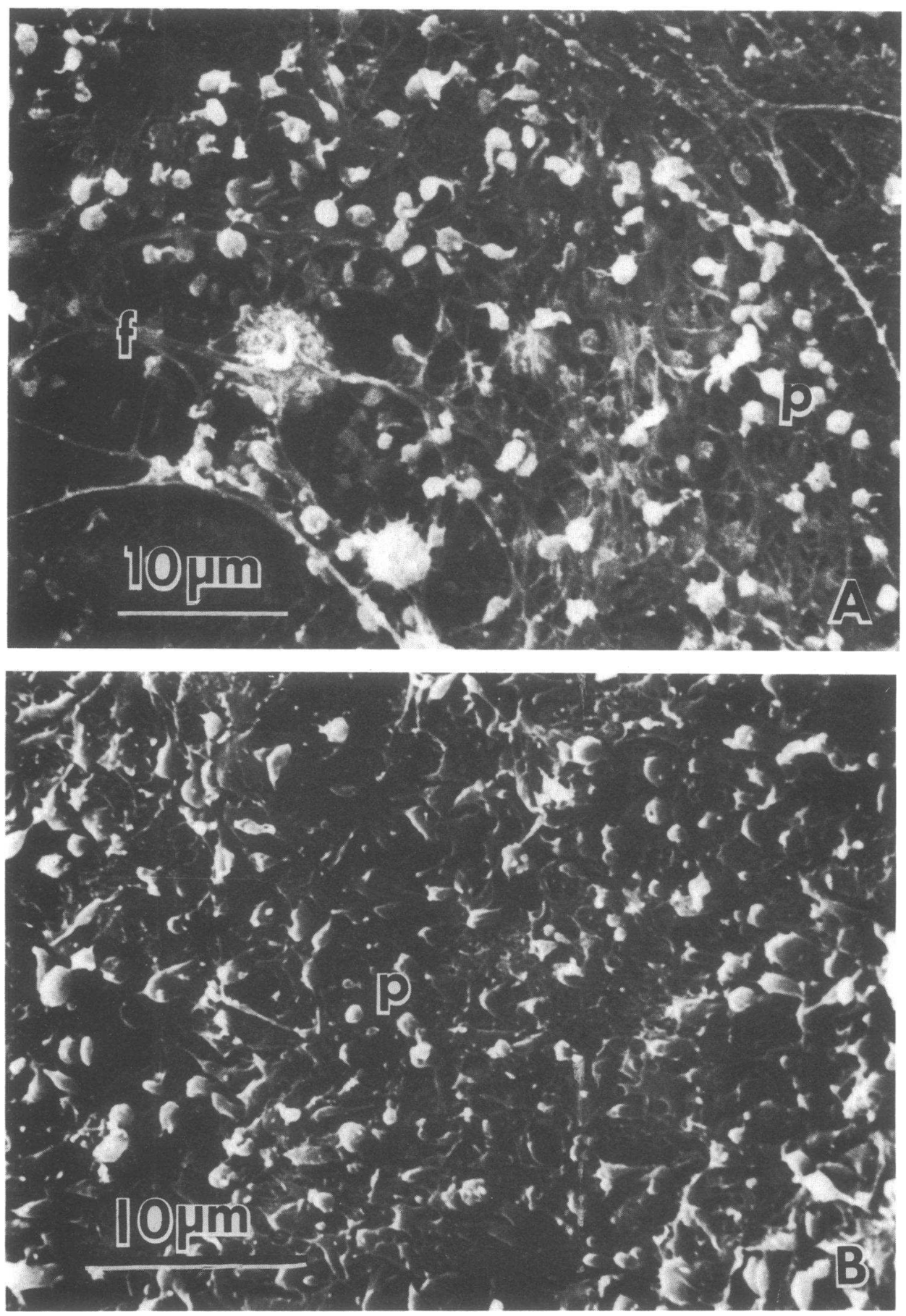

FigURE 1 Scanning electron micrographs of the injured vessel walls of rats with indwelling aortic catheters. A. Platelets and fibrin on the vessel wall of a rat that had been treated with EACA over an 11-h period before the specimen was prepared. B. A lower magnification of the platelet layer on the aorta of a rat that had received a placebo solution over the 11-h period before the sample was prepared. C. This picture of the vessel wall of a rat that had received a placebo solution over an 11-h period before the specimen was prepared was taken at a higher magnification; no fibrin is apparent on the surface. 


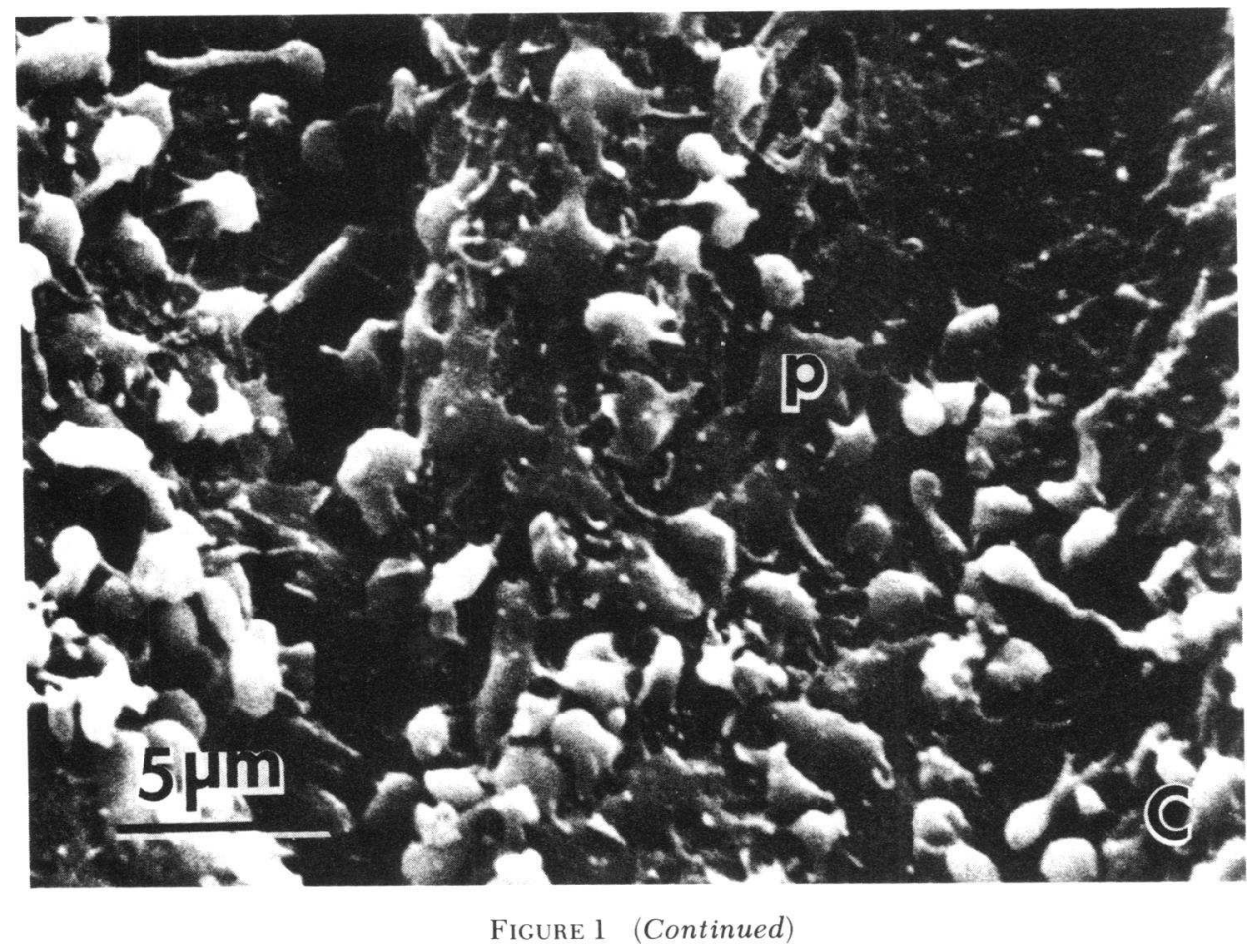

plasmin formed by activation of plasminogen in plasma would have a significant effect on the platelets because plasmin would be rapidly neutralized by the normal inhibitors in plasma (24). However, activation of plasmin or other proteolytic enzymes on the surface of the vessel where the platelets are in contact with the wall, could have a localized effect on the platelets. In earlier experiments, Niewiarowski et al. (25) found that the infusion of high concentrations of streptokinase into rabbits altered platelet function and shortened platelet survival.

Green and associates $(26,27)$ found that EACA inhibits platelet function and prolongs the bleeding time, raising the possibility that the effects of EACA may be mediated through an effect on platelet function. A number of studies have demonstrated that inhibition of platelet aggregation does not necessarily correlate with shortened platelet survival $(28,29)$. Furthermore, at the concentration used in these experiments in rats, EACA did not inhibit platelet function.

If stimulation or injury of the endothelium or the vessel wall does lead to local plasmin formation and the activation of other proteolytic enzymes, platelets that interact at these sites could be altered in such a way that their survival is shortened. If this is the case, then shortened platelet survival may be more a re- flection vessel wall injury or stimulation than of thromboembolic events.

\section{ACKNOWLEDGMENT}

This work was supported by grants-in-aid from the Medical Research Council of Canada (MT 1309) and the Ontario Heart Foundation.

\section{REFERENCES}

1. Somers, D., R. L. Kinlough-Rathbone, H. M. Groves, M. A. Packham, and J. F. Mustard. 1980. Platelet incorporation into thrombi and platelet survival in rabbits. Fed. Proc. 39: 629.

2. Winocour, P. D., M. Cattaneo, R. L. Kinlough-Rathbone, and J. F. Mustard. 1981. Vessel injury, thrombosis and platelet survival. Thromb. Haemostasis. 46: 912.

3. Meuleman, D. G., G. M. T. Vogel, and A. M. L. van Delft. 1980. Effects of intra-arterial cannulation on blood platelet consumption in rats. Thromb. Res. 20: 4555.

4. Buchanan, M. R., C. J. Carter, and J. Hirsh. 1979. Decreased platelet thrombogenecity in association with in creased platelet turnover and vascular damage. Blood. 54: 1369-1375.

5. Packham, M. A., M. A. Guccione, R. L. Kinlough-Rathbone, and J. F. Mustard. 1980. Platelet sialic acid and platelet survival after aggregation by ADP. Blood. 56: 876-880. 
6. Reimers, H-J., R. L. Kinlough-Rathbone, J-P. Cazenave, A. F. Senyi, J. Hirsh, M. A. Packham, and J. F. Mustard. 1976. In vitro and in vivo functions of thrombin-treated platelets. Thromb. Haemostas. 35: 151-166.

7. Greenberg, J. P., M. A. Packham, M. A. Guccione, M L. Rand, H.-J. Reimers, and J. F. Mustard. 1979. Survival of rabbit platelets treated in vitro with chymotrypsin, plasmin trypsin, or neuraminidase. Blood. 53: 916-927.

8. Ardlie, N. G., M. A. Packham, and J. F. Mustard. 1970. Adenosine diphosphate-induced platelet aggregation in suspensions of washed rabbit platelets. $\mathrm{Br}$. J. Haematol. 19: 7-17.

9. Murphy, E. A., and D. R. Bolling. Platelet survival. 1978 In Platelet Function Testing. H. J. Day, H. Holmsen, and M. B. Zucker, editors. DHEW Publication No. (NIH) 78: 1087. p. 561-567.

10. Scheffel, U., P. A. McIntyre, B. Evatt, J. A. Dvornicky, T. K. Natarajan, D. R. Bolling, and E. A. Murphy. 1977. Evaluation of Indium-111 as a new high photon yield gamma emitting "physiological" platelet label. Johns Hopkins Med. J. 140: 285-293.

11. Turpie, A. G. G., E. Genton, P. Han, A. C. de Boer, and M. Gent. 1980. Evaluation of gamma function calculation of platelet survival time (PST). Circulation. 62(Suppl. III): 277

12. Moroz, L. A., and N. J. Gilmore. 1975. A rapid and sensitive ${ }^{125}$ I-fibrin solid-phase fibrinolytic assay for plasmin. Blood. 46: 543-553.

13. Greenberg, J., M. A. Packham, J.-P. Cazenave, H.-J Reimers, and J. F. Mustard. 1975. Effect on platelet function of removal of platelet sialic acid by neuraminidase. Lab. Invest. 32: 476-484.

14. Cazenave, J.-P., M. A. Packham, and J. F. Mustard. 1973. Adherence of platelets to a collagen-coated surface: development of a quantitative method. J. Lab. Clin. Med. 82: 978-990.

15. Kinlough-Rathbone, R. L., H.-J. Reimers, J. F. Mustard, and M. A. Packham. 1976. Sodium arachidonate can induce platelet shape change and aggregation which are independent of the release reaction. Science (Wash. DC). 192: 1011-1012.

16. Groves, H. M., R. L. Kinlough-Rathbone, M. Richardson. S. Moore, and J. F. Mustard. 1979. Platelet interaction with damaged rabbit aorta. Lab. Invest. 40: 194-200.

17. Caen, J. P., A. T. Nurden, C. Jeanneau, H. Michel, G Tobelem, S. Levy-Toledano, Y. Sultan, F. Valensi, and
J. Bernard. 1976. Bernard-Soulier Syndrome: a new platelet glycoprotein abnormality. Its relationship with platelet adhesion to subendothelium and with the Factor VIII von Willebrand protein. J. Lab. Clin. Med. 87: 586596.

18. Astrup, T. 1978. Fibrinolysis: an overview. In Progress in Chemical Fibrinolysis and Thrombolysis. J. F. Davidson, R. M. Rowan, M. M. Samama, and P. C. Desnoyers, editors. Raven Press, New York. 3: 1-57.

19. Astrup, T., and K. Buluk. 1963. Thromboplastic and fibrinolytic activities in vessels of animals. Circ. Res. 13: 253-260.

20. Ohlsson, K., and I. Olsson. 1974. The neutral proteases of human granulocytes. Isolation and partial characterization of granulocyte elastases. Eur. J. Biochem. 42: 519-527.

21. Harker, L. A., and S. J. Slichter. 1972. Platelet and fibrinogen consumption in man. N. Engl. J. Med. 287: 999-1005.

22. Abrahamsen, A. F. 1968. Platelet survival studies in man. Scand. J. Haematol. (Suppl.) 3: 7-53.

23. Ordinas, A., S. Maragall, R. Castillo, and A. T. Nurden. 1978. A glycoprotein I defect in the platelets of three patients with severe cirrhosis of the liver. Thromb. Res. 13: 297-302.

24. Collen, D. 1980. On the regulation and control of fibrinolysis. Thromb. Haemostas. 43: 77-89.

25. Niewiarowski, S., A. F. Senyi, and J. F. Mustard. 1972. Effect of fibrinolysis induced by streptokinase (SK) on platelet function and on platelet turnover. Third Congress of the International Society of Thrombosis and Haemostasis, Washington, DC. p. 228.

26. Green, D., C. Ts'Ao, and I. Cohen. 1981. €-aminocaproic acid inhibits platelet binding of fibrinogen. Blood. Suppl. 1: $194 \mathrm{~A}$.

27. Glick R., D. Green, C. Ts'Ao, W. A. Witt, A. T. W. Yu, and A. Raimondi. 1981. High dose $\epsilon$-aminocaproic acid prolongs the bleeding time and increases rebleeding and intraoperative hemorrhage in patients with subarachnoid hemorrhage. Neurosurgery. 9: 398-401.

28. Weily, H. S., and E. Genton. 1970. Altered platelet function in patients with prosthetic mitral valves. Effects of sulfinpyrazone therapy. Circulation. 42: 967-972.

29. Harker, L. A., and S. J. Slichter. 1972. Platelet and fibrinogen consumption in man. N. Engl. J. Med. 287: 999-1005. 